\title{
Evaluation of the contact angle and wettability of hydrophobised lightweight concrete with sawdust
}

\author{
Malgorzata Szafraniec ${ }^{1}$, Danuta Barnat-Hunek ${ }^{2}$ \\ ${ }^{1}$ Department of Construction; Faculty of Civil Engineering and Architecture; \\ Lublin University of Technology; Nadbystrzycka 40, 20-618 Lublin, Poland; \\ m.szafraniec@pollub.pl (iD 0000-0002-5862-9456 \\ 2 Department of Construction; Faculty of Civil Engineering and Architecture; \\ Lublin University of Technology; Nadbystrzycka 40, 20-618 Lublin, Poland; \\ d.barnat-hunek@pollub.pl (iD)0000-0001-8409-3299
}

Funding: This work was partially financially supported by the Polish Ministry of Science and Higher Education within the statutory research numbers FN14/ILT/2019.

\begin{abstract}
The aim of the research presented in the paper was to evaluate the feasibility of using hydrophobic preparations based on organosilicon compounds for protection treatment on the lightweight concrete modified with sawdust. The experimental part of the work concerns the physical and mechanical properties of lightweight concrete and the influence of two hydrophobic agents on the contact angle of the material. Lightweight concrete contact angle $\left(\theta_{\mathrm{w}}\right)$ was determined as a time function using one measuring liquid. Water repellent coatings in lightweight concrete structure with the coarse aggregate sawdust (CASD) using electron microscopy were presented. The effectiveness of hydrophobisation of porous lightweight concretes was determined on the basis of the research. For the hydrophobic surface, the contact angle decreased and it depended on the used agents. The lowest contact angle of $40.2^{\circ}(\mathrm{t}=0)$ was obtained for reference concrete before hydrophobisation and $112.2^{\circ}$ after hydrophobisation with a methyl-silicone resin based on organic solvent. The results of scientific research confirm the possibility to produce lightweight concretes modified with CASD with adequate surface protection against external moisture.
\end{abstract}

Keywords: sawdust, lightweight aggregate-concrete, organosilicon compounds, hydrophobisation, contact angle

\section{Introduction}

A key global concern for societies, governments and industry, especially in the wood processing and production sector, is the sustainability of production systems. This sector is well placed to provide products that enhance long-term environmental sustainability through 
products based on renewable natural resources from forests such as sawdust. Following the eco-trend in the nineteenth-century sawdust concrete was created. Due to its cost-effectiveness and lightweight, it has been well recognized [1-6]. To reduce the environmental impact, developed countries have now created opportunities for using wood waste in concrete structures. Besides sawdust in the production of building materials, the following waste materials from the wood industry is also used - wood shavings [7], wood fibre [8], wood ash [9-11], chips [12-14], cork [15], sawdust ash [16, 17].

Energy-saving blocks made from lightweight concrete are characterized by higher absorbability and they have much more pores compared to its trading equivalent, resulting from the porous structure of lightweight aggregate such as waste from the wood industry [18]. This is an essential problem when lightweight concrete mixes are designed. This causes the water transport, which is pulled up capillary (in the final product) [19], which significantly affects the heat flow process, increasing the thermal conductivity of materials several times [20, 21].

Damage caused by moisture is a major factor in the degradation of building materials [22-24]. Water repellent treatment is one of the methods of protecting the surface of lightweight aggregate-concrete $[25,26]$. As a result of hydrophobisation, the absorption of capillary water decreases, which allows for proper water vapour permeability. In the case of impregnation, the so-called polymer cement concretes (PCC), obtained by adding polymer, oligomer or monomer to the concrete mix, gained popularity. This results in concrete with better workability of the mix and increased tensile strength compared to normal concrete [27]. In the case of existing facilities, polymer impregnated concrete (PIC) obtained by impregnating hardened concrete with a monomer or prepolymer is popular. For the hydrophobisation of concrete, organosilicon compounds such as methyl-silicone resins or siloxanes are mainly applied [28, 29].

The applications of silanes for surface modification of materials [30-32] or in the mass of concretes [33] and mortars [34-36] are known from the literature. These compounds make the concrete surface non-wetting by water and corrosive compounds, such as water-soluble salts [37]. The ability of building materials to be wetted by liquids is of particular importance, e.g. during their hydrophobisation, in the effectiveness of anti graffiti agents, during surface cleaning.

Materials' contact angle is an indicator of their wettability [38]. Higher wettability occurs at low contact angle $(\mathrm{CA})<90^{\circ}$ and water repellency at high contact angle $>90^{\circ}$. For determining the surface tension [39], the surface free energy (SFE) [40] and the adhesive action [41, 42] the contact angle can be used. CA is influenced by many factors. For example, CA is affected by the type of measuring liquid or droplet sizes of measuring liquids. The surface homogeneity, contamination and surface roughness, longitudinal elasticity coefficient of material which is being tested, ambient temperature or humidity also have an influence on CA [43, 44].

The most commonly used CA measurement methods include bubble method, geometric method, direct measurement and capillary liquid growth on a sample of the tested material [38]. A very popular method of contact angle determination is direct measurement. For example, a goniometer is used to test CA in this method but also a contact angle analyzer can be used $[45,46]$.

Based on the properties of waterproofing agents, there is a possibility to increase or reduce the $\mathrm{CA}$ and thus the material surface tension, resulting in their non-wetting properties, which is connected, inter alia, to frost resistance and chemical corrosion resistance.

Examining the structure of the topcoat of waterproofed lightweight concrete with CASD regarding wettability, among other things, it will allow evaluating the material's behaviour under the presence of corrosive compounds and water. In situations where significant resist- 
ance of the surface layer of lightweight concretes to the corrosive environment is required, it is advisable to use preparations causing the highest contact angle.

\section{Materials and methods}

\subsection{Concrete mixtures}

The concrete mix consisted of CASD - lightweight with grain sizes from $8 \mathrm{~mm}$ to $16 \mathrm{~mm}$, Portland cement CEM II $32.5 \mathrm{R}$, sand with grain sizes from $0 \mathrm{~mm}$ to $2 \mathrm{~mm}$ and water from the city's water distribution system. On the basis of standards EN 206-1:2003 [47] and PN-B06265:2004 [48], an experimental formula was developed, which was used to produce specimens.

The following components must be used to make $1 \mathrm{~m}^{3}$ of lightweight concrete: CASD $-157 \mathrm{~kg}$, sand $-1350 \mathrm{~kg}$, cement $-350 \mathrm{~kg}$, water $280 \mathrm{~kg}$, superplasticizer $5.25 \mathrm{~kg}$.

Once the components were thoroughly mixed and the concrete was placed in the moulds, the concrete was compacted on a vibrating table. Immediately upon mixing of concrete components specimens with the following dimensions $150 \times 150 \times 150 \mathrm{~mm}$ were made. Concrete in the moulds was laid in two layers, each of which was vibrated until the appearance of the cement grout. For 24 hours, all specimens were prevented from losing moisture and kept at a temperature of approximately $23{ }^{\circ} \mathrm{C}$ till they were removed from the moulds. The samples were then inserted into the water tank for 14 days. By the time of the test ( 28 days after the samples are made), the specimens had ripened under constant laboratory conditions.

In accordance with standard EN 197-1 [49], Portland cement CEM II 32.5 R has been tested. The parameters of the cement CEM II $32.5 \mathrm{R}$ are shown in Tab. 1.

Table 1. Technical data of CEM II 32.5 R Portland cement. Source: own study

\begin{tabular}{lll}
\hline Parameters & Unit & \\
\hline Specific surface & $\left(\mathrm{cm}^{2} / \mathrm{g}\right)$ & 3985 \\
\hline Initial setting time & $(\mathrm{min})$ & 248 \\
\hline Compressive strength after & & \\
\hline 2 days & $(\mathrm{MPa})$ & 17.9 \\
28 days & & 43.0 \\
\hline Density & $\left(\mathrm{g} / \mathrm{cm}^{3}\right)$ & 3.02 \\
\hline Loss on ignition by mass cement & $(\%)$ & 5.0 \\
\hline Volume stability & $(\mathrm{mm})$ & $<10$ \\
\hline
\end{tabular}

Polycarboxylate ethers were used as a superplasticizer in the amount of $1.5 \%$ by weight of cement. Its density at $20^{\circ} \mathrm{C}$ was $1.065 \mathrm{~g} / \mathrm{cm}^{3}$.

The sawdust was collected from a local sawmill. They have been dried by drying in a laboratory dryer to remove any moisture that might affect the final cement-water ratio $(\mathrm{w} / \mathrm{c})$ of the concrete. They were then sieved through sieves to obtain the 8-16 mm fraction for the production of coarse aggregate sawdust (CASD) with a specific gravity of $0.36\left(\mathrm{~g} / \mathrm{cm}^{3}\right)$, a water absorption capacity of $89 \%$ and a grinding module of 3.79 .

\subsection{Methods}

The physico-mechanical properties of concrete with CASD have been established in accordance with the following standards: EN 1936:2010 [50], PN-EN 1389:2005 [51], EN 12390-7:2019 [52], EN 12390-3:2019 [53], PN-B-06250:1988 [54]. 


\subsection{Applied water repellents}

For laboratory testing, two commonly used hydrophobic agents on the market have been chosen, differing in solvent type, concentration and viscosity:

HA1 - water-based methyl-silicone resin in the potassium hydroxide,

HA2 - methyl-silicone resin based on organic solvent. presented.

In Tab. 2 , the primary characteristics of preparations that were used in the study are

Table 2. Properties of hydrophobic agents. Source: own study

\begin{tabular}{lllll}
\hline $\begin{array}{l}\text { Type } \\
\text { of formulation }\end{array}$ & $\begin{array}{l}\text { Surface tension } \\
\sigma\left(\mathrm{N} / \mathrm{m} \cdot 10^{-3}\right)\end{array}$ & $\begin{array}{l}\text { Viscosity } \\
\eta\left(\mathrm{Pa} \cdot \mathrm{s} \cdot 10^{-3}\right)\end{array}$ & $\begin{array}{l}\text { Density at } 20^{\circ} \mathrm{C} \\
\left(\mathrm{g} / \mathrm{cm}^{3}\right)\end{array}$ & $\begin{array}{l}\text { The quotient of the } \\
\text { surface tension and } \\
\text { viscosity } \sigma / \eta\end{array}$ \\
\hline HA1 & 67.92 & 1.10 & 1.20 & 61.73 \\
\hline HA2 & 24.30 & 2.85 & 0.85 & 8.54 \\
\hline
\end{tabular}

The lowest viscosity coefficient $\eta$ has a formulation with the lowest concentration of the active substance and it is an aqueous solution of HA1 formulation. Methyl-silicone resin in petrol HA2 is characterized by higher viscosity by almost $250 \%$ compared to that of preparation HA1. The highest value of the ratio of surface tension to the viscosity of solutions is shown by the water-based preparation HA1.

The study did not analyse the concentration of the preparation and the number of layers applied. It should be assumed that these factors influence the penetration capacity of the preparations and at the same time the contact angle and effectiveness of hydrophobisation.

The agents were applied twice by brush, one layer after another, so as not to interrupt the capillary action ('wet on wet' method).

\subsection{Evaluation of the contact angle}

The contact angle of the measuring liquid droplet was determined on a test stand which consists of a goniometer. The goniometer was integrated with the camera in order to take pictures of the droplets placed on the samples surface. Fig. 1 shows the measurement of the $\mathrm{CA}$ of reference samples and samples protected by hydrophobisation at the beginning of the test $\left(\mathrm{t}_{1}=0 \mathrm{~s}\right)$.

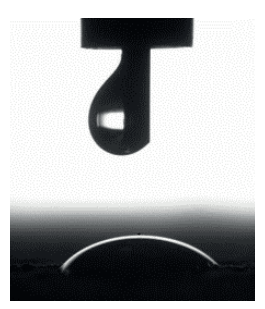

(a) $\mathrm{t}_{1}=0 \mathrm{~s}, \theta_{\mathrm{w}}=40^{\circ}$

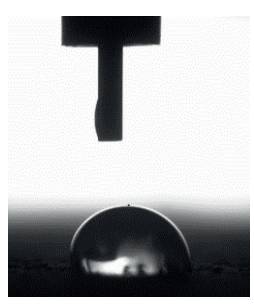

(b) $t_{1}=0 s, \theta_{\mathrm{w}}=102^{\circ}$

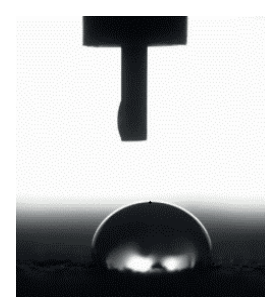

(c) $t_{1}=0 s, \theta_{\mathrm{w}}=112^{\circ}$

Fig. 1. Lightweight concrete surfaces during CA test: (a) reference sample S, (b) sample protected with agent HA1, (c) sample protected with agent HA2. Source: own study. 
For testing the CA, distilled water has been selected as the measuring liquid. The drops of liquid with a volume of $1.8 \mathrm{~mm}^{3}$ were applied with a micropipette $[38,55]$. Due to the heterogeneity of the material, 6 drops were applied to each sample. Measurements were taken 3 times: at the time of application of the drops and after 5 and 45 minutes.

\subsection{Scanning electron microscopy (SEM)}

The morphology and microtopography of water-repellent concrete with CASD were analysed using FEI Quanta 250 FEG scanning electron microscopy. The device was equipped with a chemical composition analysis system which was based on energy dispersion spectroscopy (EDS). The specimens have been formed in thin-layer tiles. They were subjected to X-ray microanalysis under field conditions and the composition of the elements for concrete were assessed.

\section{Results and analysis}

\subsection{Characteristics of lightweight concrete with CASD}

Mechanical and physical characteristics of the studied concrete are shown in Tab. 3.

Table 3. Properties of lightweight concrete with CASD. Source: own study

\begin{tabular}{llllll}
\hline $\begin{array}{l}\text { Density } \\
\rho_{\mathrm{d}}\left(\mathrm{kg} / \mathrm{m}^{3}\right)\end{array}$ & $\begin{array}{l}\text { Apparent } \\
\text { density } \\
\rho_{\mathrm{a}}\left(\mathrm{kg} / \mathrm{m}^{3}\right)\end{array}$ & $\begin{array}{l}\text { Tightness } \\
(\%)\end{array}$ & $\begin{array}{l}\text { Porosity } \\
(\%)\end{array}$ & $\begin{array}{l}\text { Compressive } \\
\text { strength }(\mathrm{MPa})\end{array}$ & $\begin{array}{l}\text { Flexural } \\
\text { strength (MPa) }\end{array}$ \\
\hline 2550 & 1504 & 59.0 & 41.0 & 26.6 & 5.9 \\
\hline
\end{tabular}

The absorbability values after 1, 3, 7 and 14 days of concrete are shown in Fig. 2.

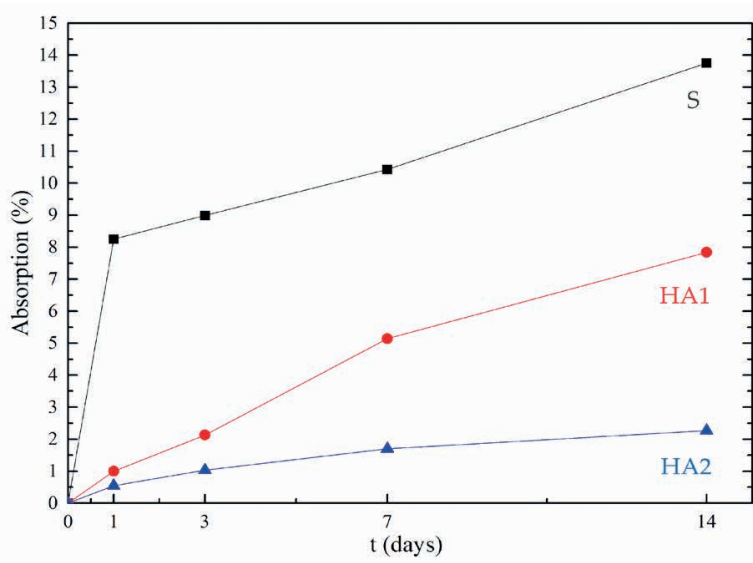

\begin{tabular}{lllll}
\hline $\begin{array}{l}\text { Type of } \\
\text { sample }\end{array}$ & \multicolumn{1}{l}{ (days) } & 3 & 7 & 14 \\
\hline S & 8.25 & 8.99 & 10.43 & 13.75 \\
\hline HA1 & 1.0 & 2.13 & 5.14 & 7.84 \\
\hline HA2 & 0.55 & 1.03 & 1.70 & 2.27 \\
\hline
\end{tabular}

Fig. 2. Absorption of concrete after 1, 3, 7 and 14 days. Source: own study

Analysing the above data, it can be seen that after 14 days of the water absorption test the reference concrete increased its mass by $67 \%$. This is due to the porosity of the concrete with CASD, which was as much as $41 \%$. This shows the need for concrete modifications to reduce 
water absorption. Thus the surface water repellent treatment was applied. The best results were obtained for concrete protected with HA2. After the first day, it reduced the water absorption of concrete by $93 \%$ and after 14 days by $83 \%$. On the last day of the test, absorbed water by concrete samples with CASD was 3.5 times lower for HA2 than for HA1.

Thalmaier G. et al. [56] made five different types of clay brick samples. The content of sawdust in the specimens was $15 \%$ for all, but they differed in the size of the sawdust fraction used to make them. They found a significant increase in water absorption from $23 \%$ to $25 \%$ depending on the sawdust fraction used. While the water absorption of the reference samples was $18 \%$. It shows a significant influence of porosity, which was $25 \%$ and up to $40 \%$ for reference samples and those with sawdust, respectively. In their research, Md Noor et al. [57] examined water absorption of concrete with palm oil kernel shells (PKS). After the research, they found that water absorption values range from $4.1 \%$ to $4.7 \%$ for the reference concrete, but increased from $4.5 \%$ to $12.1 \%$ when $25 \%$ to $75 \%$ of the coarse aggregate was replaced by PKS. This is due to the porous structure of PKS. Oba and Amadi [16] in their work created a mathematical model for water absorption of Sawdust Ash (SDA) - Sand Concrete. They replaced the fine aggregate with 5\% SDA in concrete and thus achieved a concrete water absorption rate of $3.734 \%$ to $9.568 \%$. In the paper, Castro et al. [58] showed that water absorption by concrete may also depend on the way of sample conditioning and of the volume of paste in the samples. They have shown that specimens conditioned at $50 \%$ relative humidity can exhibit almost six times higher total water absorption than similar specimens at $80 \%$ relative humidity.

The porosity of the material is the main factor on which the effectiveness of hydrophobisation depends. Water repellency is more effective as the porosity of the material increases. This is because it reaches deeper parts of the material. Szafraniec et al. in [59] showed the effectiveness of surface hydrophilisation of porous mortars with perlite. Samples surfacetreated with aqueous emulsion based on organofunctional silanes diluted in demineralised water in the ratio of 1:4 proved to be the most resistant to water absorption. Absorption of water was 7.5 times lower after 1 day and 2.9 times lower after 14 days in comparison with the reference mortars. Research conducted by Suchorab et al. [60] shows that lightweight aggregate concrete with sewage sludge, thanks to its porosity and absorbency, has absorbed more water repellent. This reduced the water absorption of this concrete by about $57 \%$. Zhu et al. [31] concluded that surface hydrophilisation of concrete with recycled aggregate reduces capillary water absorption by up to $96 \%$ and improves resistance to chloride penetration and carbonation.

\subsection{Contact angles of water}

Average wetting angles CA of water from six measurements are shown graphically in Fig. 3. Analysing the test results presented in Fig. 3, it can be seen that the values of contact angles depend on the type of hydrophobic agents.

The results of contact angle measurements showed that in all cases the contact angle $\left(\theta_{\mathrm{w}}\right)$ decreases with time. The smallest contact angle $\theta_{\mathrm{w}}=40.2^{\circ}$ was obtained for standard samples at $\mathrm{t}_{1}=0$ and the largest $\theta_{\mathrm{w}}=112.2$ at $\mathrm{t}_{1}=0$ for $\mathrm{HA} 2$, which indicates very good surface water repellency obtained by this preparation. The highest decrease by $57.2 \%$ of wetting angle value equal to $\theta_{\mathrm{w}}=23^{\circ}$ was observed after 45 minutes from applying water droplets on the reference specimens. Regarding hydrophobic concrete treated with HA2, the contact angle was reduced slightly by $7.75 \%$. The CA for HA1 decreased after 45 minutes of testing by $19.65 \%$. 


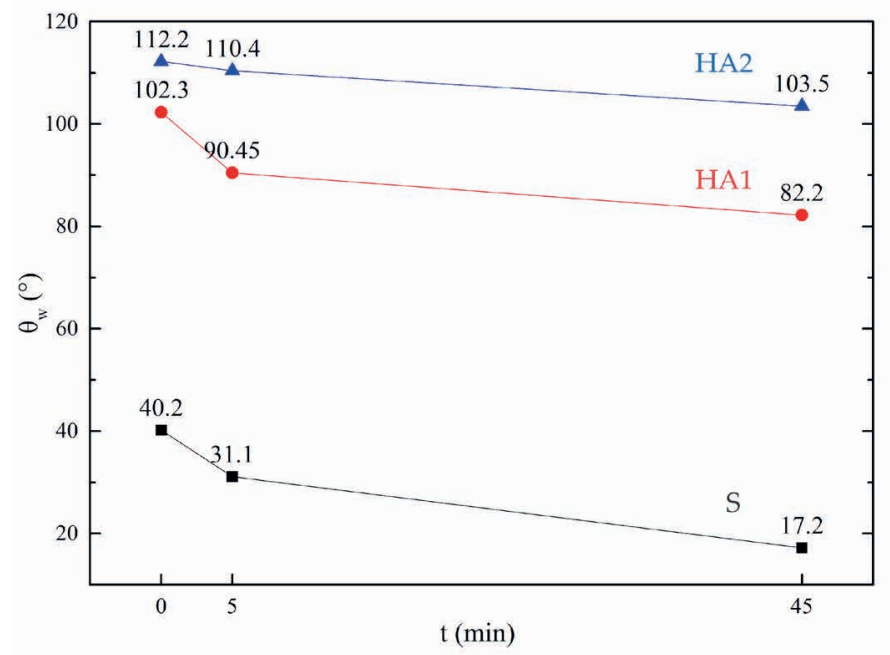

Fig. 3. CAs for lightweight concrete containing CASD. Source: own study

The use by Barnat-Hunek et al. [61] of alkyl-alkoxy-siloxanes for surface hydrophobisation of porous mortar with expanded cork resulted in 2-3 times higher contact angle compared to unprotected samples. Qu and $\mathrm{Yu}$ [62] added ground granulated blast furnace slag as a waterproof admixture to lightweight concrete. This resulted in a contact angle of $92^{\circ}$. Barnat-Hunek et al. [63] in their work showed that surface waterproofing of lightweight concrete with sewage sludge with organic solvent-based methyl silicone resin increased 60-75-fold the contact angle values (compared to reference samples). A superhydrophobic concrete (S-concrete) was created in the work of Lei et al. [64]. By using copper mesh and stearic acid they achieved a contact angle of $159^{\circ}$. Contact angle at this level has been achieved because the micro-nano-structure of S-concrete has created a stable air bubble which is trapped between the droplet and the micro-nano-composite structure. It stops the droplet and prevents the specimen surface from wetting. Fic and Szewczak [65] have tested the effectiveness of hydrophobisation of building ceramics protected by polymers which have been disintegrated by ultrasound. Moreover, to the polymers, a filler in the form of microsilica was added. In their research, they determined the contact angles for two liquids ( $w$ - water and $d$ - diiodomethane). For samples hydrophobised in pure (non-disintegrated) silicone solution, the average $\theta_{\mathrm{d}}$ value was $92^{\circ}$ and the $\theta_{\mathrm{w}}$ value was about $125^{\circ}$. In the case of samples hydrophobised in the aqueous polymer solution, which has been disintegrated by ultrasound for 15 minutes, the $\theta_{\mathrm{d}}$ value increased to $95^{\circ}$, with a $\theta_{\mathrm{w}}$ of about $129^{\circ}$. For this reason, the developed coating is more effective as it prevents the absorption of both polar liquids (water) and organic solvents (apolar). For samples immersed in a disintegrated aqueous silicone solution with the addition of microsilica, there was a significant decrease in the $\theta_{\mathrm{d}}$ value, while the $\theta_{\mathrm{w}}$ value remained above $100^{\circ}$. This indicates the preservation of the hydrophobic character of the obtained coating.

\subsection{SEM microstructural analysis}

In order to determine the effectiveness and distribution of waterproof surfaces HA1, HA2, microscopic SEM analyses were performed. Fig. 4 shows the microstructure of the concrete. 
The hardened mortar made of Portland cement consists mainly of about $67 \%$ of hydrated calcium silicates, the so-called C-S-H phases, about $22 \%$ of calcium hydroxide and products of hydration of aluminium and calcium aluminate ferroaluminium. Microscopic examination at the interface between cement mortar and CASD demonstrated good adhesion. No cracks or cavities in the joint between the two materials. Minor amounts of needle-shaped ettringite crystals are found (Fig. 4). CASD influenced the increased porosity of concrete compared with ordinary concrete.

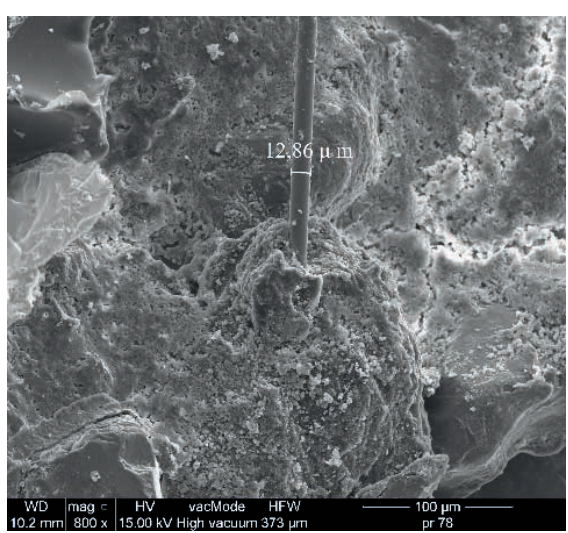

(a)

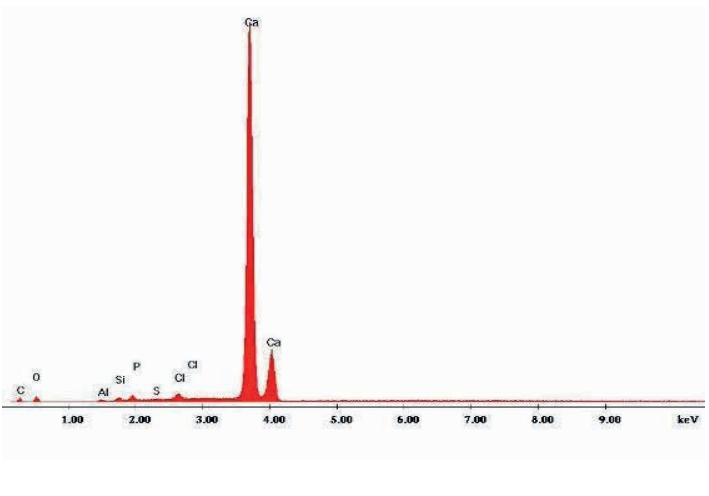

(b)

Fig. 4. The scanning microscope structure of lightweight concrete with CASD (a) and results of elemental analysis in EDS micro-area (b) - compact clusters of C-S-H phase particles can be shown. Source: own study.

The distribution of polysiloxane gel in the structure of lightweight concrete with CASD is shown in Fig. 5.

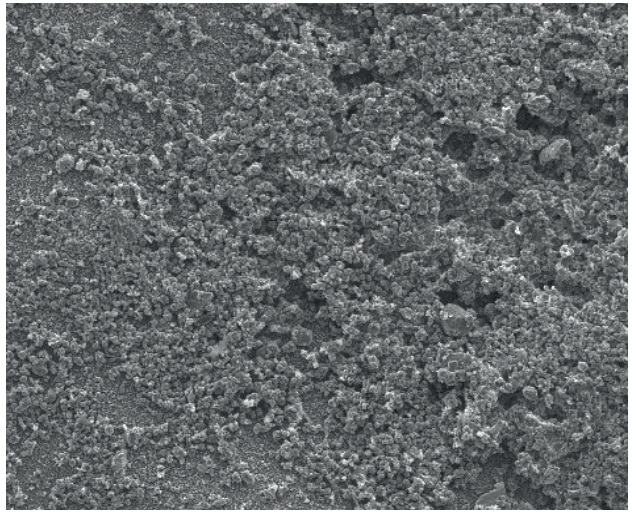

(a)

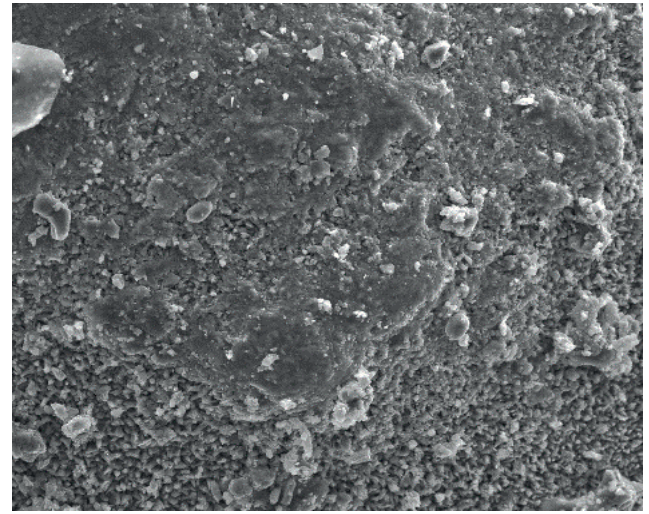

(b)

Fig. 5. The structure of hydrophobised concrete with CASD: (a) water-soluble preparation HA1, (b) methyl-silicone resin HA2. Source: own study

On the structure of the reference samples, the products used produced an evenly distributed coating without visible cracks or scratches. Agent HA2 created a silicone coating which 
covers the concrete structure most accurately (Fig. 5b). It has sealed the surface pores in this way, which may cause the porosity of the mortar to decrease slightly. In the case of CASD, their porosity remains unchanged. The preparation HA1 with an aqueous solvent has created a continuous and very thin film (Fig. 5a). HA1 has lessened the structure of lightweight concrete, which was also shown by CA measurements of a drop of water, which fell by $20^{\circ}$ after 45 minutes, while in the case of HA2 only by $8.7^{\circ}$. The decomposition of both preparations does not cause too much sealing of the pores, so they should not interfere with steam permeability and diffusion.

In the paper by $\mathrm{Qu}$ and $\mathrm{Yu}$ [62], SEM images showed that samples containing 5\% and $10 \%$ of GGBS have a denser structure. As the amount of GGBS increases, more pores appear in the concrete structure. With 20\% addition of GGBS pores larger than $20 \mu \mathrm{m}$ occurred in lightweight concrete. The SEM images shown in the work by Yoon et al. [66] pointed out the presence of calcium hydroxide and calcium silicate gels in conventional foam concrete. However, in the specimens of foam-concrete embedded in the aerogel, a large distribution of spherical nanoparticles was observed on the surface of pores and products of hydration. The structure of S-concrete shown in the study Lei et al. [64] presents a hierarchical micro-nano-structure and irregular fibres at the nanoscale. This structure contributes to the roughness of the sample surface. Furthermore, it was proved that stearic acid contributed to reducing the surface energy of the concrete and preventing the penetration of water into the concrete. Meso and micromorphology of concrete surface treated with control and superhydrophobic (SC) emulsion are presented in the paper by She et al. [67]. In the SEM images, specimens had a rough surface and consisted of multi-plane phases. The modified surface is composed of mechanically reinforced micro-pillars with a nano-roughness structure on them. The surface tomography was similar in meso- and micro-meter scale, but on the surface of concrete treated with SC there were more phases in the nanoscale. The researchers proved that the addition of silica can decrease the $\mathrm{Ca} / \mathrm{Si}$ ratio of cement hydrate in the surface layer, thus improving mechanical properties. Franczak-Balmas in her study [68] showed how roughness is an important factor. She analysed the influence of roughness of the contact surface as a parameter shaping the load-bearing capacity of the joint of the composite concrete elements. In her paper, she proved that mechanical adhesion is a key component of the contact load-bearing capacity because as the surface roughness increases (development of the contact area), load-bearing capacity increases by $60 \%$.

\section{Conclusions}

The presented studies showed that sawdust in the form of CASD can be used as additive in lightweight aggregate production. CASD can be effectively used in lightweight concrete production, which is proven with the results of physical and mechanical properties tests. The microscopic examination showed good adhesion of the contact points of cement paste and lightweight aggregates. Because of the higher absorbability and porosity caused by the CASD content in concrete, it is necessary to apply anti-moisture treatment on the surface of concrete in the form of hydrophobisation.

Measurement of the contact angle is one of ways of controlling wettability development of hydrophobised building materials. Application of different preparations leads to different wetting and adhesion properties of concrete. Lightweight concrete surface hydrophobisation has been observed to contribute to the formation of different CA. The value of CA grows noticeably on the water-repellent surface, especially with the organic solvent methyl silicone resin (HA2). For non-hydrophobic concrete, the CA values are 3-6 times lower than for the impregnated surface. 
Introduction of organo-silicon compounds into the surface zone of lightweight concrete results in a reduction of absorbability which depends on the chemical structure of the preparations. This has the effect of limiting the penetration of corrosive substances into the structure of concrete, i.e. soluble salts, toxic gases, and thus influences its durability.

\section{References}

[1] Suliman N. H. et al., "Concrete using sawdust as partial replacement of sand : Is it strong and does not endanger health ?", MATEC Web of Conferences, vol. 258, (2019), p. 01015. https://doi. org/10.1051/matecconf/201925801015

[2] Kantautas A. and Vaickelionis G., "Modified sawdust concrete", Statyba, vol. 6, no. 2, (Jan. 2000), pp. 113-119. https://doi.org/10.1080/13921525.2000.10531574

[3] Paramasivam P. and Loke Y.O., "Study of sawdust concrete", International Journal of Cement Composites and Lightweight Concrete, vol. 2, no. 1, (Mar. 1980), pp. 57-61. https://doi.org/10.1 016/0262-5075(80)90008-1

[4] Cheng Y. et al., "The Implementation of Waste Sawdust in Concrete", Engineering, vol. 05, no. 12, (Nov. 2013), pp. 943-947. https://doi.org/10.4236/eng.2013.512115

[5] Omar M. F. et al., "Partially Replacement of Cement By Sawdust And Fly Ash in Lightweight Foam Concrete", in IOP Conference Series: Materials Science and Engineering, 2020, vol. 743, no. 1. https://doi.org/10.1088/1757-899X/743/1/012035

[6] Bahtli T. and Ozbay N.S., "Corrosion resistances of C30 concrete: Effect of finely ground bronze sawdust waste", Materials Chemistry and Physics, vol. 243, (Mar. 2020), p. 122588. https://doi. org/10.1016/j.matchemphys.2019.122588

[7] Li M. et al., "Mechanical characterization of concrete containing wood shavings as aggregates", International Journal of Sustainable Built Environment, vol. 6, no. 2, (Dec. 2017), pp. 587-596. https://doi.org/10.1016/j.ijsbe.2017.12.005

[8] Sudin R. and Swamy N., "Bamboo and wood fibre cement composites for sustainable infrastructure regeneration", in Journal of Materials Science, 2006, vol. 41, no. 21, pp. 6917-6924. https://doi. org/10.1007/s10853-006-0224-3

[9] Chowdhury S. et al., "The incorporation of wood waste ash as a partial cement replacement material for making structural grade concrete: An overview", Ain Shams Engineering Journal, vol. 6, no. 2, (Jun. 2015), pp. 429-437. https://doi.org/10.1016/j.asej.2014.11.005

[10] Siddique R., "Utilization of wood ash in concrete manufacturing", Resources, Conservation and Recycling, vol. 67, (Oct. 2012), pp. 27-33. https://doi.org/10.1016/j.resconrec.2012.07.004

[11] Chowdhury S. et al., "Strength development in concrete with wood ash blended cement and use of soft computing models to predict strength parameters", Journal of Advanced Research, vol. 6, no. 6, (May 2014), pp. 907-913. https://doi.org/10.1016/j.jare.2014.08.006

[12] Drdlová M. et al., "The behavior of cement-bonded wood-chip material under static and impact load", in IOP Conference Series: Materials Science and Engineering, 2018, vol. 379, no. 1, p. 12025. https://doi.org/10.1088/1757-899X/379/1/012025

[13] Coatanlem P. et al., "Lightweight wood chipping concrete durability", Construction and Building Materials, vol. 20, no. 9, (Nov. 2006), pp. 776-781. https://doi.org/10.1016/j.conbuildmat.2005.01.057

[14] Kasai Y. et al., "Study on Wood Chip Concrete with Used Timber", Special Publication, vol. 179, (Jun. 1998), pp. 905-928.

[15] Chege J. et al., "The effects of pine (Pinus Canariensis) tree bark extract on the properties of fresh and hardened concrete.", Civil and Environmental Research, vol. 6, no. 9, (2014), pp. 70-81.

[16] Oba K. M. and Amadi I.G., "A Predictive Mathematical Model for Water Absorption of Sawdust Ash - Sand Concrete", International Journal of Engineering and Management Research, vol. 10, no. 01, (Feb. 2020), pp. 33-41. https://doi.org/10.31033/ijemr.10.1.7 
[17] Ewaen Ikponmwosa E. et al., "Experimental and numerical investigation of the effect of sawdust ash on the performance of concrete", vol. 5, (2020), p. 15. https://doi.org/10.1007/s41024-020-00081-3

[18] Oyedepo O. J. et al., "Investigation of properties of concrete using sawdust as partial replacement for sand", Civil and Environmental Research, vol. 6, no. 2, (2014), pp. 35-42.

[19] Aldred J. M. et al., "The effect of initial moisture content on water transport in concrete containing a hydrophobic admixture", Magazine of Concrete Research, vol. 53, no. 2, (Apr. 2001), pp. 127-134. https://doi.org/10.1680/macr.2001.53.2.127

[20] Demirboğa R. and Gül R., "The effects of expanded perlite aggregate, silica fume and fly ash on the thermal conductivity of lightweight concrete", Cement and Concrete Research, vol. 33, no. 5, (May 2003), pp. 723-727. https://doi.org/10.1016/S0008-8846(02)01032-3

[21] Kim H. K. et al., "Workability, and mechanical, acoustic and thermal properties of lightweight aggregate concrete with a high volume of entrained air", Construction and Building Materials, vol. 29, no. 29, (Apr. 2012), pp. 193-200. https://doi.org/10.1016/j.conbuildmat.2011.08.067

[22] Suchorab Z. et al., "Influence of moisture on heat conductivity coefficient of aerated concrete", Ecological Chemistry and Engineering S, vol. 18, no. 1, (2011), pp. 111-120.

[23] Suchorab Z. et al., "Capillary rise phenomenon in aerated concrete. Monitoring and simulations", in Proc. ECOpole 2 (4) (2010), 2010, pp. 285-290.

[24] Lo T. Y. et al., "The effect of aggregate absorption on pore area at interfacial zone of lightweight concrete", Construction and Building Materials, vol. 22, no. 4, (Apr. 2008), pp. 623-628. https:// doi.org/10.1016/j.conbuildmat.2006.10.011

[25] Tittarelli F., "Oxygen diffusion through hydrophobic cement-based materials", Cement and Concrete Research, vol. 39, no. 10, (Oct. 2009), pp. 924-928. https://doi.org/10.1016/j.cemconres.2009.06.021

[26] Suchorab Z. et al., "Free of volatile organic compounds protection against moisture in building materials", Ecological Chemistry and Engineering S, vol. 21, no. 3, (Oct. 2014), pp. 401-411. https://doi.org/10.2478/eces-2014-0029

[27] Czarnecki L., "Polymer concretes", Cement Lime Concrete, vol. 15 (2), (2010), pp. 63-85.

[28] Baltazar L. et al., "Superficial protection of concrete with epoxy resin impregnations: influence of the substrate roughness and moisture", Materials and Structures/Materiaux et Constructions, vol. 48, no. 6, (Jun. 2015), pp. 1931-1946. https://doi.org/10.1617/s11527-014-0284-9

[29] Osterholtz F. D. and Pohl E.R., "Kinetics of the Hydrolysis and Condensation of Organofunctional Alkoxysilanes: A Review", Journal of Adhesion Science and Technology, vol. 6, no. 1, (1992), pp. 127-149. https://doi.org/10.1163/156856192X00106

[30] Felekoğlu B., "A method for improving the early strength of pumice concrete blocks by using alkyl alkoxy silane (AAS)", Construction and Building Materials, vol. 28, no. 1, (Mar. 2012), pp. 305-310. https://doi.org/10.1016/j.conbuildmat.2011.07.026

[31] Zhu Y. G. et al., "Influence of silane-based water repellent on the durability properties of recycled aggregate concrete”, Cement and Concrete Composites, vol. 35, no. 1, (Jan. 2013), pp. 32-38. https://doi.org/10.1016/j.cemconcomp.2012.08.008

[32] Nakamura Y. et al., "Surface analysis of silane nanolayer on silica particles using 1H pulse NMR", Journal of Adhesion Science and Technology, vol. 25, no. 19, (Jan. 2011), pp. 2703-2716. https:// doi.org/10.1163/016942411X556079

[33] Xiong G. et al., "Influence of silane coupling agent on quality of interfacial transition zone between concrete substrate and repair materials", Cement and Concrete Composites, vol. 28, no. 1, (Jan. 2006), pp. 97-101. https://doi.org/10.1016/j.cemconcomp.2005.09.004

[34] Klisińska-Kopacz A. and Tilova R., "Effect of hydrophobization treatment on the hydration of repair Roman cement mortars", Construction and Building Materials, vol. 35, (Oct. 2012), pp. 735-740. https://doi.org/10.1016/j.conbuildmat.2012.05.002 
[35] MacMullen J. et al., "Brick and mortar treatment by cream emulsion for improved water repellence and thermal insulation", Energy and Buildings, vol. 43, no. 7, (Jul. 2011), pp. 1560-1565. https:// doi.org/10.1016/j.enbuild.2011.02.014

[36] Chmielewska B. et al., "The influence of silane coupling agents on the polymer mortar", Cement and Concrete Composites, vol. 28, no. 9, (Oct. 2006), pp. 803-810. https://doi.org/10.1016/j. cemconcomp.2006.04.005

[37] Matziaris K. et al., "Impregnation and super-hydrophobicity of coated porous low-fired clay building materials", in Progress in Organic Coatings, 2011, vol. 72, no. 1-2, pp. 181-192. https:// doi.org/10.1016/j.porgcoat.2011.03.012

[38] Rudawska A., "Selected issues on establishing adhesion bonds - homogeneous and hybrid", in Monographs - Lublin University of Technology, Lublin, 2013.

[39] European Committee for Standardization, EN 828:2013-05. Adhesives. Determining wettability by means of measuring the contact angle and critical surface tension of solid. CEN: Brussels, Belgium, 2013.

[40] Lugscheider E. and Bobzin K., "The influence on surface free energy of PVD-coatings", Surface and Coatings Technology, vol. 142, (2001), pp. 755-760. https://doi.org/10.1016/ S0257-8972(01)01315-9

[41] Baldan A., "Adhesion phenomena in bonded joints", International Journal of Adhesion and Adhesives, vol. 38, (2012), pp. 95-116. https://doi.org/10.1016/j.ijadhadh.2012.04.007

[42] Vedantam S. and Panchagnula M.V., "Constitutive modeling of contact angle hysteresis", Journal of Colloid and Interface Science, vol. 321, no. 2, (May 2008), pp. 393-400. https://doi.org/10.1016/j. jcis.2008.01.056

[43] Zielecka M., "Methods of contact angle measurement as a tool for characterization of wettability of polymers", Polimery- $W$, vol. 49, (2004), pp. 327-332.

[44] Żenkiewicz M. et al., "Contact angle and surface free energy of electron-beam irradiated polymer composites”, Polimery- $W$, vol. 53, (2008), pp. 446-451.

[45] Shang J. et al., "Comparison of different methods to measure contact angles of soil colloids", Journal of Colloid and Interface Science, vol. 328, no. 2, (Dec. 2008), pp. 299-307. https://doi. org/10.1016/j.jcis.2008.09.039

[46] Klein N. S. et al., "Evaluation of the wettability of mortar component granular materials through contact angle measurements", Cement and Concrete Research, vol. 42, no. 12, (2012), pp. 1611-1620. https://doi.org/10.1016/j.cemconres.2012.09.001

[47] European Committee for Standardization., EN 206+A1:2016-12. Concrete - Part 1: Specification, performance, production and conformity. CEN: Brussels, Belgium, 2016.

[48] Polish Committee for Standardization, PN-B-06265:2004. National supplements PN-EN 206-1:2003 Concrete - Part 1: Specification, performance, production and conformity. PKN: Warsaw, Poland.

[49] European Committee for Standardization., EN 197-1:2012. Cement-Part 1: Composition, Specifications and Conformity Criteria for Common Cements; CEN: Brussels, Belgium, 2012.

[50] Polish Committee for Standardization. and European Committee for Standardization, EN 1936:2010. Natural stone test methods - Determination of real density and apparent density, and of total and open porosity. PKN: Warsaw, Poland, 2010.

[51] Polish Committee for Standardization, PN-EN 1389:2005. Polish National Supplement: PN-EN 206-1:2003 Concrete. Specification, performance, production and conformity. PKN: Warsaw, Poland, 2005.

[52] European Committee for Standardization, EN 12390-7:2019. Testing hardened concrete. Density of hardened concrete. CEN: Brussels, Belgium, 2019. 
[53] European Committee for Standardization, EN 12390-3:2019. Testing hardened concrete - Part 3: Compressive strength of test specimens. CEN: Brussels, Belgium, 2019.

[54] Polish Committee for Standardization and Polish Committee for Standardization., PN-B06250:1988. Ordinary concrete (In Polish). PKN: Warsaw, Poland, 1988.

[55] Rudawska A. and Jacniacka E., "Analysis for determining surface free energy uncertainty by the Owen-Wendt method", International Journal of Adhesion and Adhesives, vol. 29, no. 4, (Jun. 2009), pp. 451-457. https://doi.org/10.1016/j.ijadhadh.2008.09.008

[56] Thalmaier G. et al., "Influence of sawdust particle size on fired clay brick properties", Materiales de Construcción, vol. 70, no. 338, (Mar. 2020), p. 215. https://doi.org/10.3989/mc.2020.04219

[57] Md Noor N. et al., "Compressive strength, flexural strength and water absorption of concrete containing palm oil kernel shell", in IOP Conf. Series: Materials Science and Engineering 271, 2017.

[58] Castro J. et al., "Effect of sample conditioning on the water absorption of concrete", Cement and Concrete Composites, vol. 33, no. 8, (Sep. 2011), pp. 805-813. https://doi.org/10.1016/j.cemconcomp.2011.05.007

[59] Szafraniec M. et al., "Surface Modification of Lightweight Mortars by Nanopolymers to Improve Their Water-Repellency and Durability", Materials, vol. 13, no. 6, (Mar. 2020), p. 1350. https:// doi.org/10.3390/ma13061350

[60] Suchorab Z. et al., "Mechanical and physical properties of hydrophobized lightweight aggregate concrete with sewage sludge", Materials, vol. 9, no. 5, (Apr. 2016), pp. 1-18. https://doi. org/10.3390/ma9050317

[61] Barnat-Hunek D. et al., "Properties of hydrophobised lightweight mortars with expanded cork", Construction and Building Materials, vol. 155, (Nov. 2017), pp. 15-25. https://doi.org/10.1016/j. conbuildmat.2017.08.052

[62] Qu Z. and Yu Q.L., "Synthesizing super-hydrophobic ground granulated blast furnace slag to enhance the transport property of lightweight aggregate concrete", Construction and Building Materials, vol. 191, (Dec. 2018), pp. 176-186. https://doi.org/10.1016/j.conbuildmat.2018.10.018

[63] Barnat-Hunek D. et al., "Evaluation of the Contact Angle of Hydrophobised Lightweight-Aggregate Concrete with Sewage Sludge", Ecological Chemistry and Engineering S, vol. 22, no. 4, (Jan. 2015), pp. 625-635. https://doi.org/10.1515/eces-2015-0037

[64] Lei L. et al., "Fabrication of superhydrophobic concrete used in marine environment with anti-corrosion and stable mechanical properties", Construction and Building Materials, vol. 251, (Aug. 2020), p. 118946. https://doi.org/10.1016/j.conbuildmat.2020.118946

[65] Fic S. and Szewczak A., "Hydrophobisation effectiveness of building ceramics, polymeric inorganic ultrasound integrated with the addition of fillers", Budownictwo i Architektura, vol. 14, no. 4, (Dec. 2015), pp. 019-027. https://doi.org/10.35784/BUD-ARCH.1517

[66] Yoon H. S. et al., "Thermal transfer and moisture resistances of nano-aerogel-embedded foam concrete", Construction and Building Materials, vol. 236, (Mar. 2020), p. 117575. https://doi. org/10.1016/j.conbuildmat.2019.117575

[67] She W. et al., "Superhydrophobic concrete with enhanced mechanical robustness: Nanohybrid composites, strengthen mechanism and durability evaluation", Construction and Building Materials, vol. 247, (Jun. 2020), p. 118563. https://doi.org/10.1016/j.conbuildmat.2020.118563

[68] Franczak-Balmas D., "Analiza wpływu szorstkości powierzchni styku jako parametru kształtującego nośność styku zespolonych elementów betonowych”, Budownictwo i Architektura, vol. 16, no. 3, (Dec. 2017), pp. 125-134. https://doi.org/10.24358/Bud-Arch_17_163_12 
